\title{
Electro-oxidation of tetracycline in methanol media on $\mathrm{DSA}^{\circledR}{ }_{-}-\mathrm{Cl}_{2}$
}

\author{
Rodrigo de Mello ${ }^{\mathrm{a}}$, Manuel A. Rodrigo ${ }^{\mathrm{b}}$, Artur J. Motheo ${ }^{\mathrm{a},{ }^{*}}$
}

(a) São Carlos Institute of Chemistry, University of São Paulo, P.O. Box 780, CEP 13560-970, São Carlos, SP, Brazil

(b) Department of Chemical Engineering, Faculty of Chemical Sciences \& Technologies, Universidad de Castilla - La Mancha, Campus Universitario s/n, 13071 Ciudad Real, Spain

*Corresponding author

Phone: +55 1633739932

E-mail: artur@iqsc.usp.br 


\begin{abstract}
The electro-oxidation of tetracycline $(\mathrm{TeC})$ in methanol medium containing chloride or sulfate ions was evaluated using a DSA ${ }^{\circledR}-\mathrm{Cl}_{2}$ in a flow reactor and compared with BDD. The results show that after 30 min of electrolysis no $\mathrm{TeC}$ is detected by liquid chromatography when chloride is used as supporting electrolyte. On the other hand, after 90 min of electrolysis using a BDD anode only $61 \%$ of $\mathrm{TeC}$ was removed from solutions with chloride, but in the presence of sulfate the removal reaches $94 \%$. This evidences that the oxidizing species generated during electrochemical oxidation control the process and the mechanism of degradation of the TeC. Besides that, it was possible to infer that only a small amount of methanol might convert to formaldehyde or formic acid, although they were not detected according to the nil changes in the FTIR spectra or in the HPLC chromatograms recorded.
\end{abstract}

\title{
Keywords
}

Electrochemical oxidation; tetracycline; methanol; DSA ${ }^{\circledR}$ 


\section{Introduction}

With the development of new techniques increasingly sensitive to the detection of substances, new contaminants have been found in water bodies, whether continental or oceanic, and in atmospheric air. Scientific community knows these contaminants as Emerging Pollutants (EP's). They have concentrations in the order of $\mu \mathrm{g} \mathrm{L^{-1 }}$ and include a wide variety of compounds, such as pharmaceuticals, microplastics, surfactants, pesticides, personal care products, plasticizers and preservatives and food additives (Petrović et al., 2003). Even being found in low concentrations, EP's can reach the environment from several ways, but the most part of them reach water bodies from domestic sewage treatment plants, hospital wastewater, livestock and agriculture activities (De la Cruz et al., 2012).

Among the pharmaceuticals, the antibiotics are the group of most worries by scientific community, because of their wide use by humans and animal to treat infections (Santos et al., 2020). The human and animal body is not capable of metabolize completely the antibiotics, so they are eliminated by feces and urine, and reach the environment via domestic sewage (Parra et al., 2016). Their fate in water bodies and their bioaccumulation is an increasing environmental and human health concern (Desbiolles et al., 2018). Tetracyclines have a wide spectrum of antimicrobial activity and have been used to treat various types of bacterial infections, besides being used in food preservation, and microbial control of fermentation (Parra et al., 2016).

Conventional water treatment plants are not able to remove EP's completely and, besides that, organic contaminants with high toxicity can inhibit the action of microorganisms and even destroy bacterial cultures during biological treatment (Diez, 2010). Among the methods for removing contaminants, electrochemical processes have gained a lot of attention due to the advantages over traditional methods and have proved to be efficient in removing pesticides (Malpass et al., 2012; Santos et al., 2014, 2015; Souza et al., 2016; de Mello et al., 2018; Muñoz-Morales et al., 2019a), pharmaceuticals (Parra et al., 2016; Hussain et al., 2017; Garcia-Segura et al., 2018; GarcíaEspinoza and Nacheva, 2019), personal care products (Gomes et al., 2016; Frontistis et al., 2017; 
Steter et al., 2018; Ding et al., 2019; Dionisio et al., 2019), textile residues (Rajkumar and Kim, 2006; Malpass et al., 2007, 2008; Alves et al., 2010) and another contaminant classes (Fornazari et al., 2012; Souza et al., 2014a, 2014b). In this process, the properties of electrode material are very important, and the use of highly efficient and stable electrocatalytic electrodes makes electrochemical methods even more attractive. As examples of this type of electrodes, one can mention the commercial dimensionally stable anode $\left(\mathrm{DSA}^{\circledR}\right.$, a type of mixed metal oxide electrode (MMO) used widely on chlor-alkali industry) and the boron-doped diamond (BDD). The first stands out for the electrochemical generation of substances with high oxidative power from the anions contained in the solution (Martínez-Huitle et al., 2015), being specially relevant for the production of chlorine species (Tomcsányi et al., 1999). Besides that, it can produce hydroxyl radicals, which are strongly adsorbed on the surface, making these electrodes very active for $\mathrm{O}_{2}$ evolution and leading to selective oxidation of contaminants. On the other hand, the BDD anode has a high capacity for generating hydroxyl radicals poorly adsorbed and it presents higher oxygen evolution overpotential. These characteristics favor the oxidation of organic compounds and are lower effective for $\mathrm{O}_{2}$ evolution (Pelskov et al., 1987; Comninellis, 1994).

Despite that, the electrochemical treatment of wastes with low concentration of contaminant is commonly inefficient because of diffusional limitations that occurred in the electrochemical cell and the high energetic costs (Sirés et al., 2014; Martínez-Huitle et al., 2015; Muñoz-Morales et al., 2019a). It is because the electrolysis of diluted wastes fits well with the first order kinetics so, it is required the same applied electric charge to reduce a given percentage of the initial concentration, regardless of the initial concentration value (Muñoz-Morales et al., 2019a).

Thus, an alternative to improve the efficiency of the electrochemical process is to pre-concentrate the contaminant. Some methods have been shown to be viable, such as electrocoagulation for colloid concentration (Muñoz et al., 2017) and the use of electrodialysis to ionic species concentration (Raschitor et al., 2017). The adsorption process is interesting to be used, once it presents low initial cost, high flexibility, simplicity, easy operation and high efficiency, being 
widely employed in water treatment plants. The mechanisms of adsorption can be physical, chemical or competitive. Van der Waals or dispersion force drives the first one. The chemical adsorption is related with the chemical reaction, which occur between surface functional groups of adsorbent and adsorbate molecules (Zhu et al., 2020). The main advantage of the chemical adsorption is the higher selectivity than physical adsorption. In this case, it is very important that the substance adsorbed being removed with an appropriate solvent, and more than that, this solvent must have properties that enable it to be used in electrochemical oxidation processes. As far as we know, electrolysis performed in non-aqueous media is a new issue and there is just a few works in the literature (Ayata et al., 2013; Saravanan et al., 2013). Other works include electro reduction (Farzinnejad et al., 2005; Wain et al., 2006; Chanique et al., 2013) or the organic synthesis (Inprakhon et al., 2017; Suresh et al., 2018) were studied.

Taking into account this background, the aim of the present work has been to evaluate the possibility of using $\mathrm{DSA}^{\circledR}$ as anode in the electrochemical oxidation of tetracycline hydrochloride in methanol or methanol/water solutions. These types of solutions are expected to be produced during the pre-concentration procedure carried out by a sequential adsorption onto GAC and desorption using methanol as solvent as reported elsewhere (Muñoz-Morales et al., 2019a, 2019b, 2020) in combined processes in which diamond electrolysis was successfully combined with this pre-concentration stage. Because of that, the electrolysis of the resulting solution was also carried out using BDD anode to compare the efficiency of both electrodes in the presence of some amount of $\mathrm{NaCl}$ or $\mathrm{H}_{2} \mathrm{SO}_{4}$. Besides that, the behavior of methanol was analyzed. Finally, a possible mechanism of degradation in this medium was proposed.

\section{Experimental}

\subsection{Chemical products}

Tetracycline hydrochloride (TeC, $\mathrm{C}_{22} \mathrm{H}_{24} \mathrm{~N}_{2} \mathrm{O}_{8} . \mathrm{HCl}$, >95\%) was supplied from Sigma-Aldrich. Methanol HPLC grade (99.9\% - Panreac Química, Brazil) was used as solvent and mobile phase 
in HPLC, along with acetonitrile HPLC grade (99.98\% - J.T. Baker) and oxalic acid P.A. (99.5 $102.5 \%$ - Synth) $0.01 \mathrm{M}$. Deionized water (Millipore Milli-Q system, resistivity: $18.2 \mathrm{M} \Omega \mathrm{cm}^{-1}$ at $25^{\circ} \mathrm{C}$ ) was used when necessary. All the chemicals were used as received without further purification.

\subsection{Analytical techniques}

The voltammetric response for both DSA ${ }^{\circledR}$ and BDD electrodes was evaluated at $50 \mathrm{mV} \mathrm{s}^{-1}$ using a PGSTAT128N potentiostat/galvanostat (Metrohm Autolab B.V., The Netherlands), controlled by the software Nova 2.0. An $\mathrm{Ag} / \mathrm{AgCl}$ electrode was used as reference. The measurements were performed in four different electrolytes: methanol with $0.05 \mathrm{M}$ of $\mathrm{NaCl}$. Methanol with $0.05 \mathrm{M}$

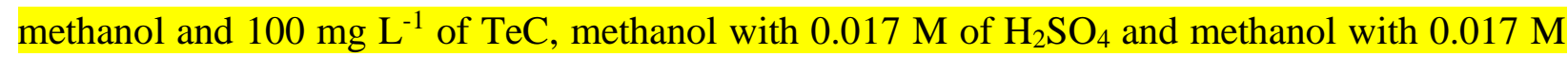
$\mathrm{H}_{2} \mathrm{SO}_{4}$ and with $100 \mathrm{mg} \mathrm{L}^{-1}$ of $\mathrm{TeC}$. The different concentration of sodium chloride and sulfuric acid were chosen in order to keep the same ionic strength.

The concentration of $\mathrm{TeC}$ during electrooxidation experiments was monitored by highperformance liquid chromatograph (HPLC, Shimadzu, LC-10AD VP) with UV detector (Shimadzu, SPD-10A VP). Stationary phase was Ascentis ${ }^{\circledR}$ C-18 reversed phase column (Supelco, $3 \mu \mathrm{m}, 150 \mathrm{~mm} \times 4.6 \mathrm{~mm}$ ). The eluent was a mixture of methanol, acetonitrile and oxalic acid $0.01 \mathrm{M}$, at isocratic mode, in a volumetric proportion 40:5:55, operating with flow of $0.5 \mathrm{~mL} \mathrm{~min}{ }^{-}$ ${ }^{1}$, with detection wavelength at $360 \mathrm{~nm}$ and the furnace temperature was kept in $40{ }^{\circ} \mathrm{C}$.

Analysis of the reaction products of methanol electrochemical oxidation were performed using HPLC (Shimadzu, LC-10AD VP) with an ion exchange column Aminex ${ }^{\circledR}$ (Bio-Rad, HPX-87H, $9 \mu \mathrm{m}, 300 \mathrm{~mm} \times 7.8 \mathrm{~mm}$ ) as described elsewhere (Malpass and Motheo, 2001; Batista et al., 2004).

The eluent was $\mathrm{H}_{2} \mathrm{SO}_{4} 3.33 \mathrm{M}$ operating with flow of $0.6 \mathrm{~mL} \mathrm{~min}^{-1}$, with detection in a UV detector (Shimadzu, SPD-10A VP) at $\lambda=210 \mathrm{~nm}$ followed by a refractive index detector (RID-10A VP). The first one was used to detect the carboxylic acid and the second for methanol and aldehyde. The products were identified by comparing the retention times against reference chemicals. The 
concentration of oxidants produced during the electrolysis process was determined by iodometric titration (Andrade, 2018).

The infrared spectra of the samples were measured by attenuated total reflection-Fourier transform infrared (ATR-FTIR). It was used a FTIR spectrometer VERTEX 70 (Bruker Corporation, Germany) coupled with a diamond crystal ATR. The spectra were taken at a spectral resolution of $4 \mathrm{~cm}^{-1}$, and to each measurement 32 scans were performed.

\subsection{Experimental set-up}

To determine the removal efficiency of $\mathrm{TeC}$ in methanol or water medium and in methanol “contaminated" with water $(2.5 \%, \mathrm{v} / \mathrm{v})$, solutions with $100 \mathrm{mg} \mathrm{L}^{-1}$ of $\mathrm{TeC}$ and $0.050 \mathrm{M} \mathrm{NaCl}$ or $0.017 \mathrm{M} \mathrm{H}_{2} \mathrm{SO}_{4}$ (supporting electrolyte) were prepared. The different concentrations were used to maintain the ionic strength in $0.050 \mathrm{M}$.

The differences between a Ti/ $\mathrm{Ru}_{0.3} \mathrm{Ti}_{0.7} \mathrm{O}_{2}\left(\mathrm{DSA}^{\circledR}\right)$ anode (supplied by DeNora S.A., Brazil) and a Boron-Doped Diamond (BDD) anode (supplied by CONDIAS GmbH, Germany) were studied in a single-compartment filter-press flow cell. In the case of the DSA ${ }^{\circledR}$ anode, a titanium cathode was used, with an apparent geometric area of $14.81 \mathrm{~cm}^{2}$, separated by Viton ${ }^{\circledR}$ and Teflon ${ }^{\circledR}$ spacers, as described elsewhere (Gomes et al., 2011). For the BDD system, it was used one stainless-steel cathode, both with an apparent geometric area of $80 \mathrm{~cm}^{2}$, and ethylene propylene diene monomer spacer/sealer. In both cases, the treatment of $0.7 \mathrm{~L}$ of solution was carried out in flow regime using a jacketed reservoir with $0.7 \mathrm{~L}$ of capacity and a peristaltic pump (Solar - model SL-64) at flow rate of $42 \mathrm{dm}^{3} \mathrm{~h}^{-1}$. The temperature of the reservoir was kept at $21 \pm 2{ }^{\circ} \mathrm{C}$ using a thermostatic bath. The applied current density was $10 \mathrm{~mA} \mathrm{~cm}{ }^{-2}$ during $1 \mathrm{~h}$ and it was provided by a power supply (Missipa - MPL-3303). This current density was chosen, since in a previous test at $20 \mathrm{~mA}$

$\mathrm{cm}^{-2}$, the removal of $\mathrm{TeC}$ was very fast, which made it impossible to determine the kinetic behavior. 
Prior to use, for both system setup, the anode was polarized for 20 min in $\mathrm{H}_{2} \mathrm{SO}_{4} 0.05 \mathrm{M}$ solution at $40 \mathrm{~mA} \mathrm{~cm}{ }^{-2}$ to remove any impurities from its surface. For chromatographic analyses, $2 \mathrm{~mL}$ aliquots were taken from the reservoir at different times during the electrolysis process.

\section{Results and discussion}

\subsection{Electrochemical oxidation of TeC}

Fig. 1 shows the voltametric response of $\operatorname{DSA}^{\circledR}$ (Fig. 1a) and BDD (Fig. 1b) electrodes in different methanol solutions, which contain chlorides or sulfates anions, alone and with $100 \mathrm{mg} \mathrm{L}^{-1}$ of TeC. As it can be seen, intensities are much higher in the case of the $\mathrm{DSA}^{\circledR}$, pointing out a higher electrochemical response than that of BDD in the four electrolytes tested. Also important to note that with both electrodes, intensities recorded in sulfate are higher than those obtained in chloride containing electrolytes, despite electrolytes had the same ionic strength. Similar to what occurs in aqueous supporting electrolytes[1], there is a large electrochemical window using BDD electrode in methanol medium. This was also confirmed in a previous work focus on the same technology (Muñoz-Morales et al., 2019a) and means that oxidants can be produced more efficiently with diamond electrodes. The addition of $\mathrm{TeC}$ to the sulfate and chloride methanol solutions leads to an increase in the current produced, indicating that $\mathrm{TeC}$ is oxidized on the electrode surface with both electrodes. However, changes are more relevant with the BDD electrode, pointing out that direct electrolysis is also more significant in the electrolysis made with this anode. In addition, an oxidation peak in the nearness $0.5 \mathrm{~V}$ is observed when $\mathrm{TeC}$ is present, showing that $\mathrm{TeC}$ is oxidized at this potential on the BDD anode surface. This peak is masked by the decomposition of the electrolyte in the voltammetries made with DSA ${ }^{\circledR}$. 


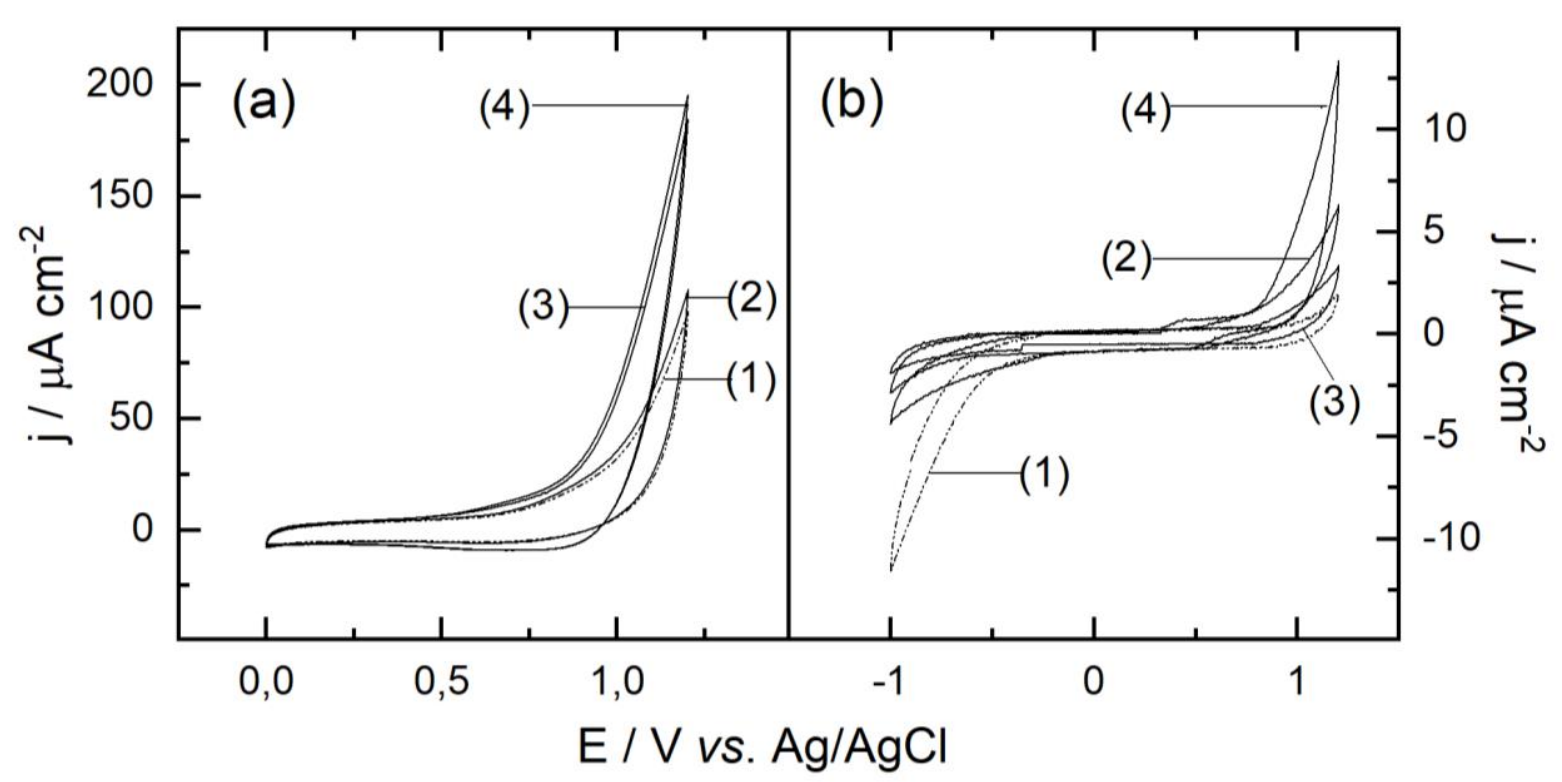

Fig. 1. Cyclic voltammograms for (a) DSA ${ }^{\circledR}$ and (b) BDD electrodes with different electrolytes: (1) methanol/ $\mathrm{NaCl}$; (2) methanol/ $\mathrm{NaCl}$ with $100 \mathrm{mg} \mathrm{L}{ }^{-1}$ of $\mathrm{TeC}$; (3) methanol/ $\mathrm{H}_{2} \mathrm{SO}_{4}$; and (4) methanol/ $\mathrm{H}_{2} \mathrm{SO}_{4}$ with $100 \mathrm{mg} \mathrm{L}^{-1}$ of TeC (4). Auxiliary electrode: Ti plate for DSA ${ }^{\circledR}$ and stainlesssteel for BDD; Reference electrode: $\mathrm{Ag} / \mathrm{AgCl}$. Scan rate: $50 \mathrm{mV} \mathrm{s}^{-1}$.

Fig. 2 shows the electrochemical oxidation of TeC solutions $\left(100 \mathrm{mg} \mathrm{L}^{-1}\right)$ carried out in methanol, water and a mixture of $97.5 \%$ methanol and $2.5 \%$ water, using the DSA ${ }^{\circledR}$ (Fig. 2a) and BDD (Fig. 2b). TeC was completely removed from all solutions using the active one. During the first 10 min, the removal rate of $\mathrm{TeC}$ was practically the same, regardless of the solvent, with $0.05 \mathrm{Ah} \mathrm{L}^{-1}$ of electric charge being sufficient to remove $92 \%$ and $98 \%$ of $\mathrm{TeC}$ from solutions containing methanol or water, respectively, and $91 \%$ from solution composed of the solvent mixture. On the other hand, electrolysis performed with BDD anode showed less removal of the contaminant from methanol solution, as can be seen in Fig. 2b, and after 90 min of electrolysis it was still possible to detect the presence of $\mathrm{TeC}$. In this case, after applying an electric charge of approximately 2.0 $\mathrm{Ah} \mathrm{L}^{-1}$, only $61 \%$ of $\mathrm{TeC}$ were removed from the methanol solution and $55 \%$ from the methanol-water mixture solution. In an aqueous media, $0.38 \mathrm{Ah} \mathrm{L}^{-1}$ were required to remove about $97 \%$ of TeC. This amount of electric charge is almost ten times greater than that needed to remove 
the same percentage of $\mathrm{TeC}$ using the $\mathrm{DSA}^{\circledR}$. Besides that, in the first few minutes of electrolysis, a quick removal of $\mathrm{TeC}$ occurs: in $10 \mathrm{~min}$, about $90 \%$ of $\mathrm{TeC}$ was already removed. For comparison purposes, the theoretical decrease for a $100 \%$ current efficiency is also shown in Figure 2 considering complete mineralization of the antibiotic $(90 \mathrm{mmol} \mathrm{e}-/ \mathrm{mmol} \mathrm{TeC})$. As seen, the decays observed experimentally are faster than those required for mineralization confirming the production of intermediates that are more refractory than the parent $\mathrm{TeC}$.
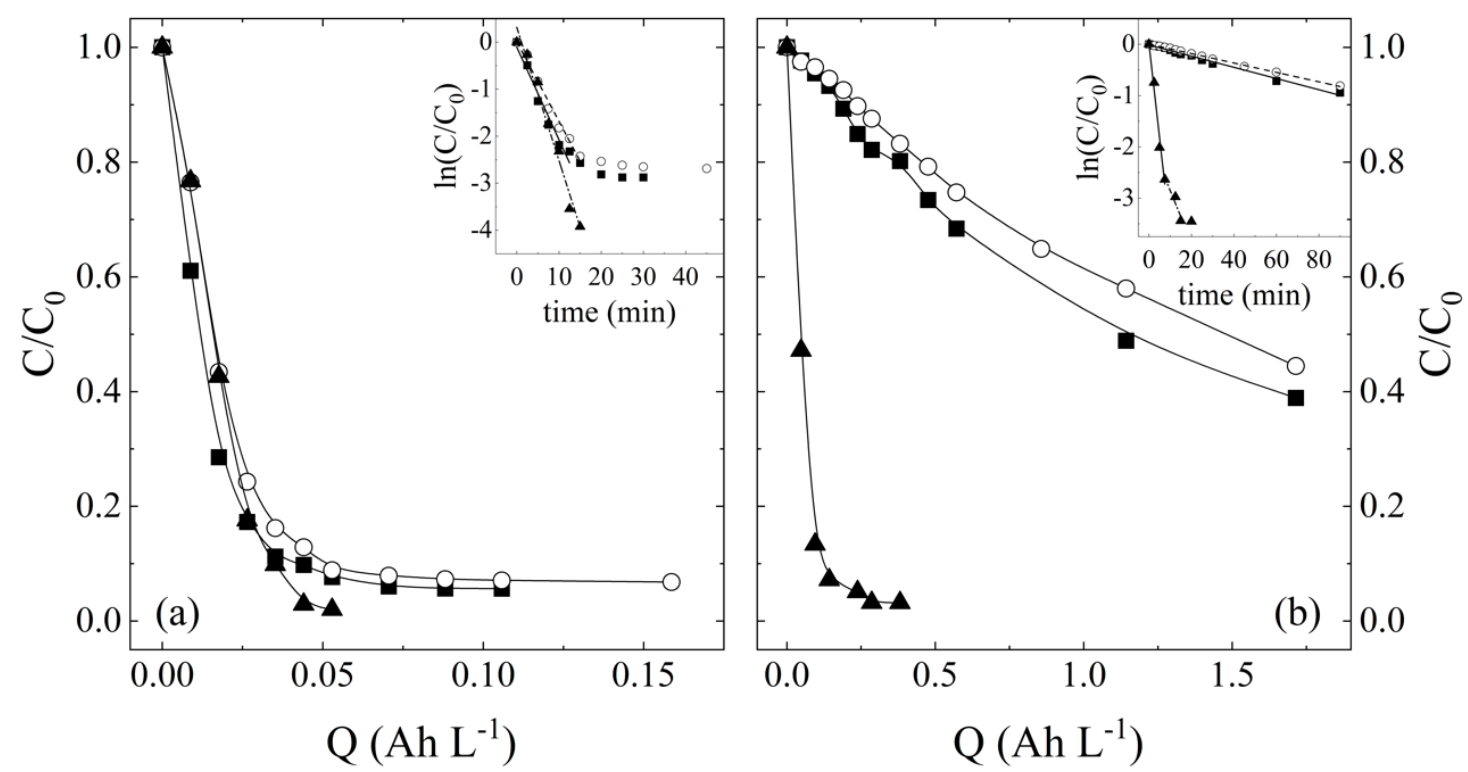

Fig. 2. Electrochemical removal of $\mathrm{TeC}\left(100 \mathrm{mg} \mathrm{L}^{-1}\right)$, as the function of the instant applied electric

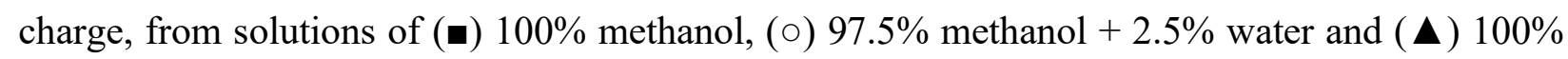
water as solvent. Anode: (a) DSA ${ }^{\circledR}$ and (b) BDD. Supporting electrolyte: $\mathrm{NaCl} 0.050$ M. Applied current density: $10 \mathrm{~mA} \mathrm{~cm}^{-2}$. Inset: kinetic analysis considering a pseudo-first order reaction.

Fig. 3 shows the concentration of oxidants produced during the electrolysis processes. In aqueous media, both electrodes produce higher concentration of oxidants than in methanol media. This fact impacts directly on electrochemical oxidation of $\mathrm{TeC}$. As observed, $\mathrm{TeC}$ was removed faster when water was used as solvent. Besides that, using BDD, it can be verified a maximum concentration of oxidants production at around $150 \mathrm{~min}$ of electrolysis, while with DSA increase the concentration of oxidants continuously on that solutions. It's very important to take in mind that 
the oxidants produced by each electrode are different: DSA ${ }^{\circledR}$ electrodes are very active for active chorine species (e.g., $\mathrm{Cl}_{2}, \mathrm{HClO}$ and $\mathrm{ClO}^{-}$) when $\mathrm{Cl}^{-}$is present in the solution and this species are the mainly responsible for indirect oxidation (Tomcsányi et al., 1999; Dionisio et al., 2020); on the other hand, BDD produces higher amount of perchlorate by oxidation of chloride (Brillas and Martínez-Huitle, 2015). In addition, the oxidation power of these species may play an important effect on $\mathrm{TeC}$ removal and this can be an important drawback for it, even in methanol media. As can be observed, in methanol media, both electrodes produce almost the same concentration of oxidants. However, due the different species generated by each electrode, values for TeC removal are very different. Note that, in water, BDD produces a higher quantity of hydroxyl radicals than $\mathrm{DSA}^{\circledR}$ (Comninellis, 1994)[2-4] and that explains why, in that case, the contaminant removal is higher and faster using BDD than DSA ${ }^{\circledR}$. Finally, ruthenium electroactive from $\mathrm{Ti} / \mathrm{Ru}_{0.3} \mathrm{Ti}_{0.7} \mathrm{O}_{2}$ may act as catalyst in the electro-oxidation of organic contaminants, although in this case its contribution to $\mathrm{TeC}$ removal is expected to be negligible once when $\mathrm{Cl}^{-}$are present, these anions occupy the active sites of the $\mathrm{DSA}^{\circledR}$ electrode.

Figure 4 shows the concentration of oxidants agents produced during the electrolysis process. As ean be observed, in aqueous media, there was a great number of oxidants being produced. As expected, using BDD as an anode, a large amount of hydroxyl radical can be produced, and this production was confirmed by the high concentration determined. In the case of DSA ${ }^{\circledR}$, chlorinated species can be produced in larger quantities than in BDD. It is important to remember that DSA ${ }^{\circledR}$ ean produce active chlorine species $\left(\mathrm{Cl}_{2}, \mathrm{HClO}\right.$ and $\left.\mathrm{ClO}^{-}\right)$that are the mainly responsible for indirect oxidation (Dionisio et al., 2020). When chloride is present in the solutions, BDD produces higher amount of perchlorate and this can be an important drawback for TeC removal (Brillas and Martínez-Huitle, 2015). In addition, the oxidation power of the species may play an important effect on TeC removal: in water, for example, there is a higher production of hydroxyl radical with BDD than with DSA ${ }^{\circledR}$ anodes, which has a standard reduction potential of $2.80 \mathrm{~V} / \mathrm{SHE}$ (GarciaSegura et al., 2018), with a high oxidative power, involving in a faster removal of the contaminant. 
In methanol media, the situation reverses: BDD does not have this advantage, while DSA ${ }^{\circledR}$ promotes the more efficient formation of the active chlorine species. In addition, ruthenium electroactive from $\mathrm{Ti} / \mathrm{R} \mathrm{U}_{0.3} \mathrm{Ti}_{\theta_{.7}} \Theta_{z}$ - may act as catalyst in the electro-oxidation of organic contaminants, although in this case its contribution to $\mathrm{TeC}$ removal is expected to be negligible once when $\mathrm{Cl}^{-}$are present, these anions occupy the active sites of the DSA ${ }^{\circledR}$ electrode.

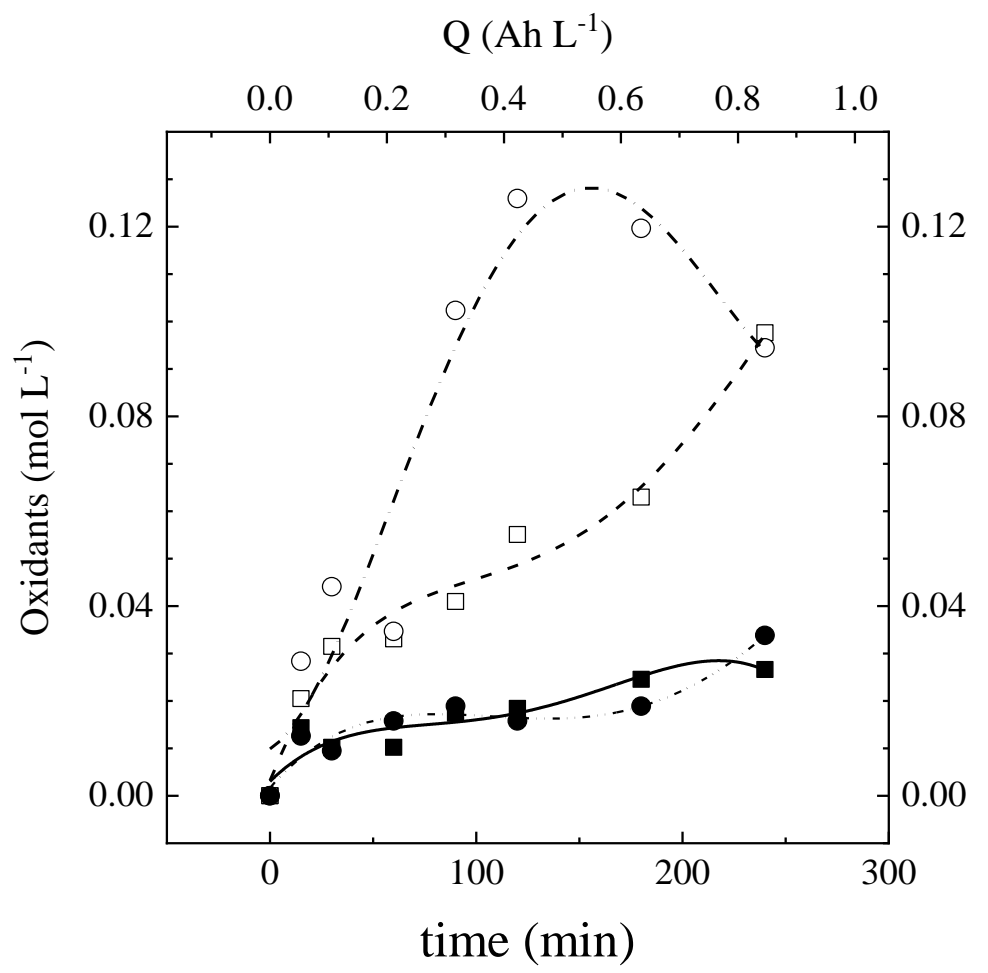

Fig. 3. Concentration of oxidants produced during the electrolysis in methanol $(\bullet, \mathbf{\square})$ and aqueous medium (o, 口) using DSA ${ }^{\circledR}$ (square) and BDD (circle). Electrolyte: $0.050 \mathrm{M} \mathrm{NaCl}$.

The electrolysis was also performed in the presence of sulfate anions (sulfuric acid solutions). As can be seen in the Fig. 4, a much higher removal was promoted when BDD was used. When using $\mathrm{DSA}^{\circledR}$ less than $25 \%$ of $\mathrm{TeC}$ was removed with a kinetic constant of $0.0358 \pm 0.0008 \mathrm{~s}^{-1}$, while with BDD, almost $95 \%$ of the contaminant was degraded with a kinetic constant of $0.405 \pm 0.004 \mathrm{~s}^{-}$ 1. It indicates that the oxidizing species produced during the electrolysis control the removal of $\mathrm{TeC}$ in methanol media, once that BDD is able to convert sulfate to persulfate, promoting the contaminant removal and DSA ${ }^{\circledR}$ does not. (Brillas and Martínez-Huitle, 2015). 


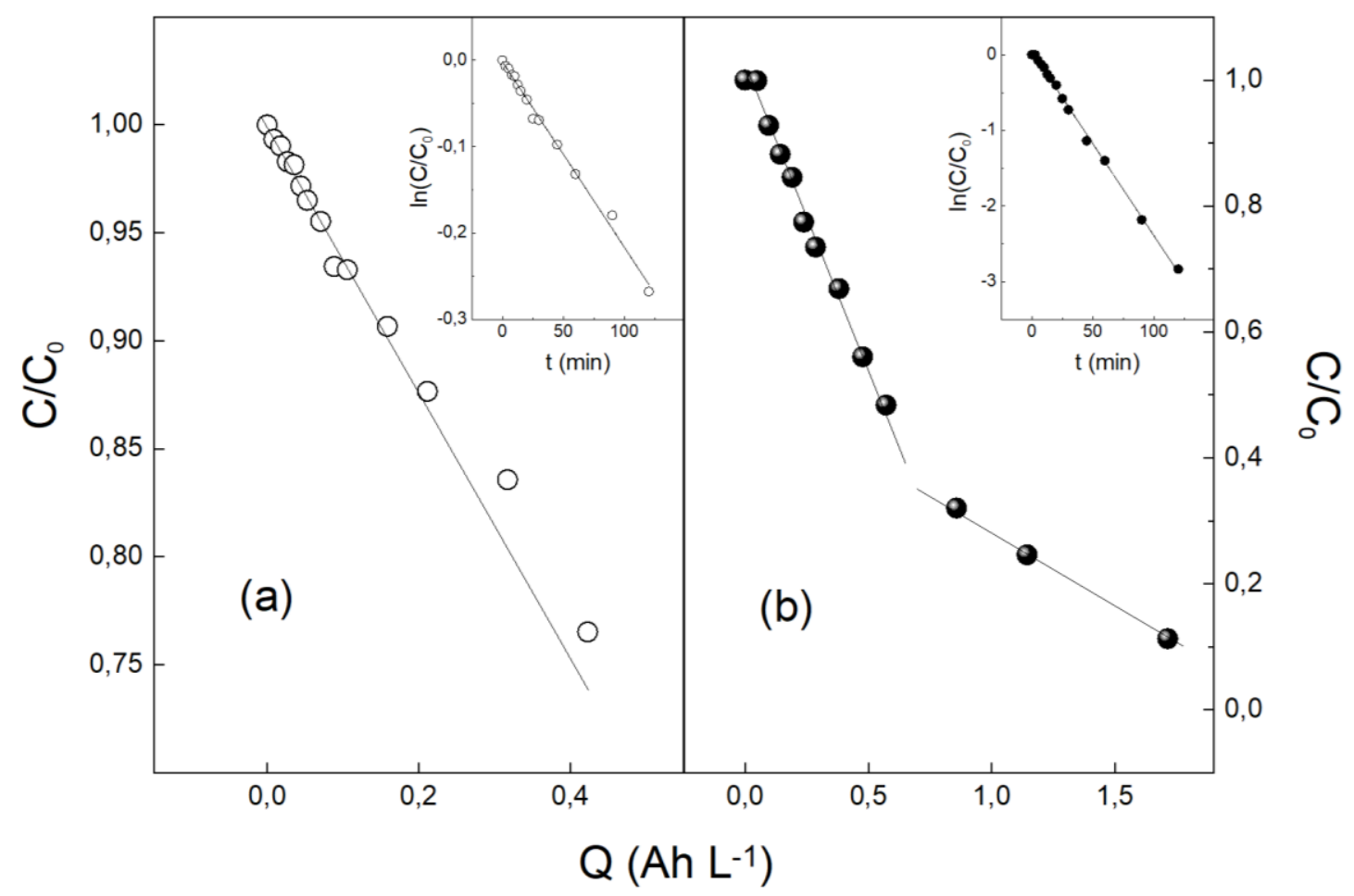

Fig. 4. Electrochemical removal of $\mathrm{TeC}\left(100 \mathrm{mg} \mathrm{L}^{-1}\right)$, as the function of the instant applied charge, from solutions of $100 \%$ methanol using $\operatorname{DSA}^{\circledR}$ (a) and BDD (b) as anode. Supporting electrolyte: $\mathrm{H}_{2} \mathrm{SO}_{4}$ 0.017 M. Applied current density: $10 \mathrm{~mA} \mathrm{~cm}{ }^{-2}$. Inset: kinetic analysis considering a pseudofirst order reaction.

Electrochemical oxidation processes are dependent on the nature of the electrode material (Brillas and Martínez-Huitle, 2015). The BDD is characterized as inert and presenting physio-adsorption and, therefore, in aqueous media, a large part of the hydroxyl radical is produced from water and organic oxidation is mediated by these radicals, which can result in reaction products totally oxidized (Marselli et al., 2003; Brillas and Martínez-Huitle, 2015). Thus, the lower removal of TeC in methanol when BDD is used, may be related only to the prevention in the formation of strongly oxidizing radicals due to the absence of water, but also to the direct oxidation on the anode surface. Furthermore, the formation of methanoate radicals is possible (Muñoz-Morales et al., 2020) even in low quantity. However, further analysis will be necessary for confirmation. 
On the other hand, DSA ${ }^{\circledR}$ electrodes in chloride medium are capable to generate chlorine oxidative species, in particular, hypochlorous acid and hypochlorite ion (Santos et al., 2020b) even when methanol was used as solvent. Meanwhile, perchlorate ions are predominant when BDD is used and the chloride anion is oxidized to non-useful oxochlorine compounds such as perchlorate, for example, when the non-active anode is used (Sánchez-Carretero et al., 2011; Santos et al., 2020c). When $\mathrm{H}_{2} \mathrm{SO}_{4}$ was used as supporting electrolyte the performance of BDD increased. It shows that the supporting electrolyte play an important role in the mechanism for $\mathrm{TeC}$ removal.

\subsection{Kinetic analysis}

It is important to note that for both in methanol (with or without the presence of water) and in aqueous media, the concentration decay of $\mathrm{TeC}$ with both anodes obeys a first order kinetics. This behavior is very common in the removal of organic compounds by electrochemical oxidation in aqueous medium (Malpass and Motheo, 2001; Vedenyapina et al., 2008; Parra et al., 2016; Santos et al., 2020a). The values for the first order kinetics constants are shown in the Table 1. In methanol/ $\mathrm{NaCl}$, with and without water, the kinetics constants present very close values in both cases, $\mathrm{DSA}^{\circledR}$ and BDD. Furthermore, there is no statistical difference between the constants for the electrochemical oxidation performed using the active anode. For the processes performed in aqueous medium, the values for the constants are higher than for methanol solutions, as expected, since the large production of chlorinated oxidants, in the case of the DSA ${ }^{\circledR}$, and hydroxyl radicals for the BDD. Comparing the kinetic constants for methanol/ $\mathrm{H}_{2} \mathrm{SO}_{4}$ and methanol/ $\mathrm{NaCl}$ is possible to observe the large difference in the performance of DSA ${ }^{\circledR}$ anode.

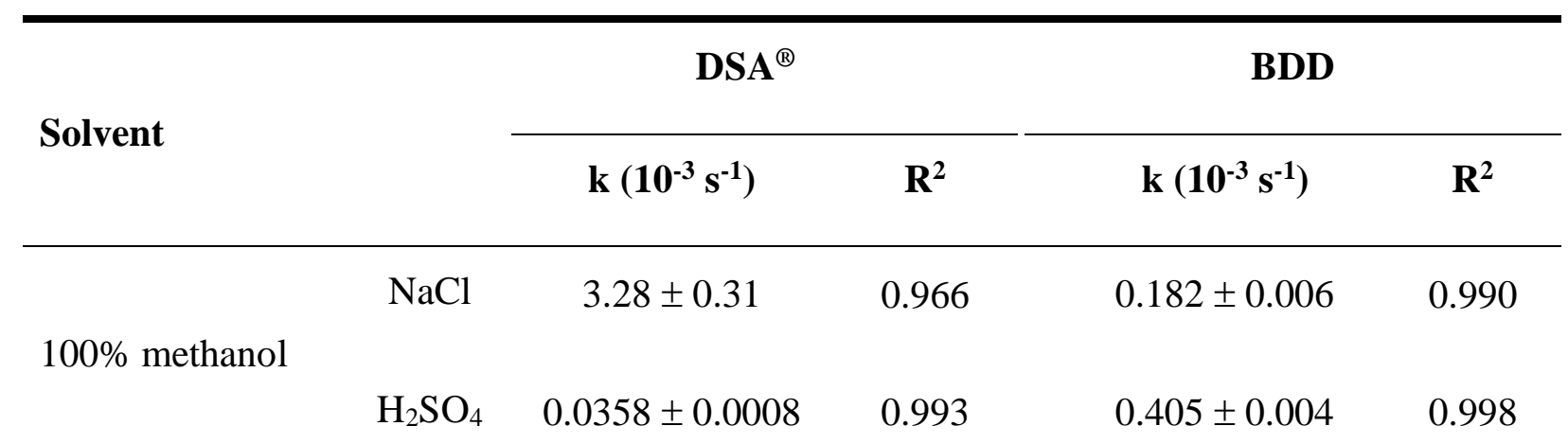




$\begin{array}{lccccc}\begin{array}{l}97.5 \% \text { methanol }+ \\ 2.5 \% \text { water }\end{array} & \mathrm{NaCl} & 2.82 \pm 0.16 & 0.985 & 0.153 \pm 0.002 & 0.998 \\ 100 \% \text { water } & \mathrm{NaCl} & 4.72 \pm 0.32 & 0.977 & 6.12 \pm 0.55 & 0.984\end{array}$

Table 1. First-order kinetic constants of TeC electrolysis in methanol-water solutions

The electrolysis carried out using the BDD electrode shows a different behavior, dependent on the solvent. In the case of the experiments performed in methanol media there was no peak associated to intermediate products, as can be observed in chromatograms presented in the Fig. SM-1a and SM-1b. This can occur because of the instantaneous oxidation of intermediates, as soon as they are formed. It was also verified for electrochemical oxidation of lindane in the study carried out by Muñoz-Morales et al. (Muñoz-Morales et al., 2019a). For TeC removal in aqueous media, the intermediates are not removed as fast, as can be seen in the Fig. SM-2, and were detected by HPLC (Fig. SM-1c). Nevertheless, as can be seen in the Fig. 5, after 15 min of electrolysis they were no longer detected. As previously said, in the first $10 \mathrm{~min}$ of electrolysis about $90 \%$ of $\mathrm{TeC}$ was removed. This causes two different kinetic behaviors, as can be seen in the inset of Fig. 2b. At first, a kinetic constant of $6.12 \mathrm{~s}^{-1}$ was found, and after $10 \mathrm{~min}$ this constant was reduced to $1.70 \mathrm{~s}^{-}$ 1. This behavior was also observed by Dionisio et al. (2019) and it may be related with a change in the oxidation mechanism during the electrolysis.

On the other hand, when DSA ${ }^{\circledR}$ was used, a wide variety of intermediates was detected (Fig. SM3, SM-4, SM-5 and SM-6). Most of them were detected in very low concentration and they were oxidized very quickly. In methanol media, after $45 \mathrm{~min}$ of electrolysis, the intermediates were no detected. Meanwhile, in aqueous medium they were detected up to $60 \mathrm{~min}$ of experiment (Fig. 5). The largest peak area of intermediates was found in the first 5 min of electrolysis in the case of the experiments carried out in methanol media using $\mathrm{DSA}^{\circledR}$ and in aqueous medium using BDD. In the case of aqueous medium using DSA ${ }^{\circledR}$, it can be found after $7.5 \mathrm{~min}$. It is important to note that, in this case, TeC was detected only up to 15 min of electrolysis, but the intermediates remained in the solution for up to $60 \mathrm{~min}$. In the methanol media used, TeC was no longer detected after 25 
min and the intermediates remained up to $45 \mathrm{~min}$. Since all organic compounds $(\mathrm{TeC}+$ oxidation products) have been completely removed in methanol, it is possible that complete TeC mineralization has occurred. Unfortunately, it is not possible to determine the removal of TOC, due to the large amount of methanol present as a solvent, which masks any changes in the antibiotic or intermediates.

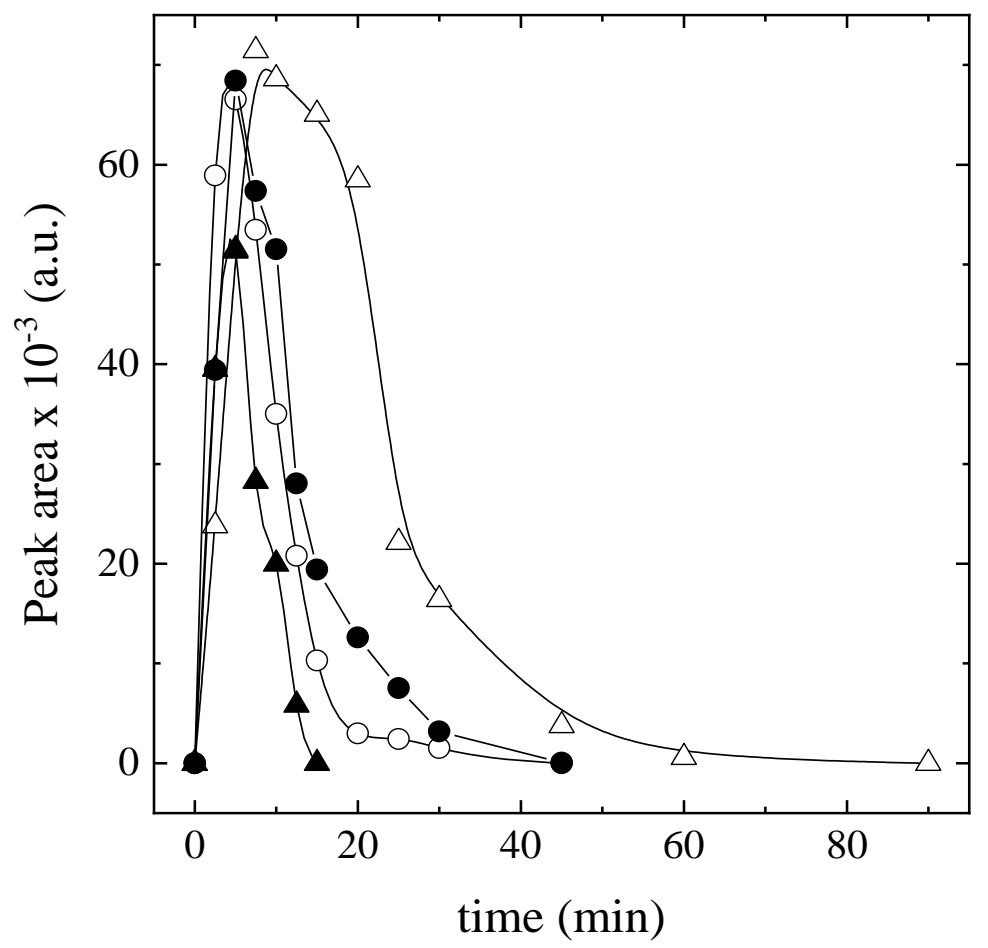

Fig. 5. Peak area of the intermediates detected as function of electrolysis time of (O) $100 \%$ methanol $\left(\mathrm{DSA}^{\circledR}\right),(\bullet) 97.5 \%$ methanol $+2.5 \%$ water $\left(\mathrm{DSA}^{\circledR}\right),(\triangle) 100 \%$ water $\left(\mathrm{DSA}^{\circledR}\right)$ e $(\mathbf{\Delta})$ $100 \%$ water (BDD) solutions containing TeC.

\subsection{Effect of solvent electrolysis}

Experiments using methanol without the contaminant were performed to verify if the solvent changes during the electrolysis. Some studies have shown that methanol electrooxidation occurs via parallels pathways forming $\mathrm{HCHO}, \mathrm{HCOOH}$ and $\mathrm{CO}_{2}$ (Ota et al., 1984; Malpass and Motheo, 2001; Batista et al., 2003, 2004). In this case, methanol was used as a solvent, it is extremely important to ensure that this substance is not consumed or altered during the experiments. 
From the analysis of the FTIR spectra in the Fig. 6, it was possible to see the characteristics IR absorption for alcohols associated with both the $\mathrm{O}-\mathrm{H}$ (a broad and strong band) and the C-O stretching vibrations, located in the region $3500-3200 \mathrm{~cm}^{-1}$ and $1260-1050 \mathrm{~cm}^{-1}$, respectively. C$\mathrm{H}$ stretch was also detected in the region $3000-2700 \mathrm{~cm}^{-1}$. Results are according with Doroshenko et al. (Doroshenko et al., 2013) and the NIST library. As can be seen, there is no significant difference between the spectra over electrolysis time.

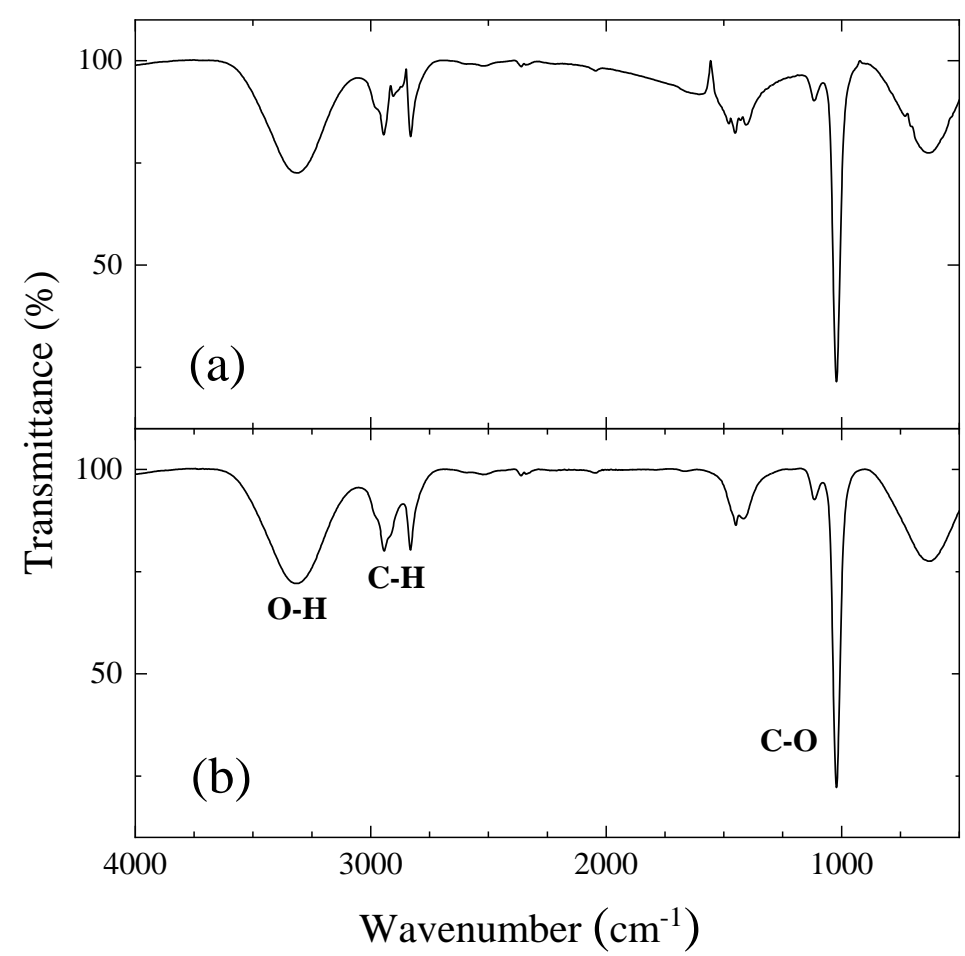

Fig. 6. FTIR spectra for the methanol electrochemical oxidation using DSA ${ }^{\circledR}$. Samples taken at (a) 0 and (b) $240 \mathrm{~min}$.

Fig. SM-7 shows the UV-vis spectra for those samples. As can be observed, the absorbance increases in the wavelength from 320 to $200 \mathrm{~nm}$. This result can be related an increase in the formaldehyde and formic acid concentration. These substances present a retention time of 13.6 min for the aldehyde and 14.2 min for the acid by the HPLC method. As can be seen in the Fig. SM-8, both substances were not detected. Therefore, it can be concluded that the substances are produced in a very low concentration, which can evaporate during handling, and does not change the nature of the solvent, despite the increase in absorbance verified by UV-vis. 


\section{Conclusions}

This study shows that it is possible to remove organic compounds using electrochemical oxidation in methanol media. Using DSA ${ }^{\circledR}$ as anode, complete removal was achieved in $1 \mathrm{~h}$ with solutions containing chloride ions, even in the presence of $2.5 \%$ of water. On the other hand, while with chloride-supporting electrolyte the removal of $\mathrm{TeC}$ was about $60 \%$ with the use of BDD anode, using sulfate-supporting electrolyte the performance of this anode reaches $94 \%$ being higher than the efficiency of the DSA ${ }^{\circledR}$. This shows that the oxidant agents produced during the electrolysis control the process and the mechanism of degradation of TeC. It was possible to observe that methanol does not change during electrolysis and only a small amount of formaldehyde or formic acid were suspected to be formed, although they were not detected according to the negligible changes in the FTIR spectra or the nil variations in the HPLC chromatograms recorded.

\section{Acknowledgments}

Financial support from the São Paulo Research Foundation (FAPESP, Brazil) [2017/10118-0, 2017/20444-1, 2018/16308-8 and 2020/03052-5] and from the Spanish Ministry of Economy, Industry and Competitiveness, European Union through project PID2019-107271RB-I00 (AEI/FEDER, UE) are gratefully acknowledged. The authors would also like to thank Embrapa Instrumentation, Brazil. 


\section{References}

Alves, P.A., Malpass, G.R.P., Johansen, H.D., Azevedo, E.B., Gomes, L.M., Vilela, W.F.D., Motheo, A.J., 2010. Photo-assisted electrochemical degradation of real textile wastewater. Water Sci. Technol. 61, 491-498. https://doi.org/10.2166/wst.2010.870

Andrade, J.C. de, 2018. Determinações iodométricas. Rev. Chemkeys 1-6. https://doi.org/10.20396/chemkeys.v0i2.9623

Ayata, S., Stefanova, A., Ernst, S., Baltruschat, H., 2013. The electro-oxidation of water and alcohols at BDD in hexafluoroisopropanol. J. Electroanal. Chem. 701, 1-6. https://doi.org/10.1016/j.jelechem.2013.03.024

Batista, E.A., Malpass, G.R.P., Motheo, A.J., Iwasita, T., 2003. New insight into the pathways of methanol oxidation. Electrochem. Commun. $\quad$ 543-846. https://doi.org/10.1016/j.elecom.2003.08.010

Batista, E.A., Malpass, G.R.P., Motheo, A.J., Iwasita, T., 2004. New mechanistic aspects of methanol oxidation. J. Electroanal. Chem. 571, 273-282. https://doi.org/10.1016/j.jelechem.2004.05.016

Brillas, E., Martínez-Huitle, C.A., 2015. Decontamination of wastewaters containing synthetic organic dyes by electrochemical methods. An updated review. Appl. Catal. B-Environ. 166167, 603-643. https://doi.org/10.1016/j.apcatb.2014.11.016

Chanique, G.D., Arévalo, A.H., Zonn, M.A., Fernandezn, H., 2013. Eletrochemical reduction of patulin and 5-hydroxymethylfurfural in both neutral and acid non-aqueous media. Their electroanalytical determination in apple juices. Talanta 111, 85-92. https://doi.org/10.1016/j.talanta.2013.02.041

Comninellis, C., 1994. Electrocatalysis in the electrochemical conversion/combustion of organic pollutants for waste water treatment. Electrochim. Acta 39, 1857-1862. 
https://doi.org/10.1016/0013-4686(94)85175-1

De la Cruz, N., Giménez, J., Esplugas, S., Grandjean, D., De Alencastro, L.F., Pulgarín, C., 2012. Degradation of 32 emergent contaminants by UV and neutral photo-fenton in domestic wastewater effluent previously treated by activated sludge. Water Res. 46, 1947-1957. https://doi.org/10.1016/j.watres.2012.01.014

de Mello, R., Santos, L.H.E., Pupo, M.M.S., Eguiluz, K.I.B., Salazar-Banda, G.R., Motheo, A.J., 2018. Alachlor removal performance of $\mathrm{Ti} / \mathrm{Ru}_{0.3} \mathrm{Ti}_{0.7} \mathrm{O}_{2}$ anodes prepared from ionic liquid solution. J. Solid State Electr. 22, 1571-1580. https://doi.org/10.1007/s10008-017-3700-6

Desbiolles, F., Malleret, L., Tiliacos, C., Wong-Wah-Chung, P., Laffont-Schwob, I., 2018. Occurrence and ecotoxicological assessment of pharmaceuticals: Is there a risk for the Mediterranean aquatic environment? Sci. Total Environ. 639, 1334-1348. https://doi.org/10.1016/j.scitotenv.2018.04.351

Diez, M.C., 2010. Biological aspects involved in the degradation of organic pollutants. J. Soil Sci. Plant Nut. 10, 244-267. https://doi.org/10.4067/S0718-95162010000100004

Ding, J., Bu, L., Zhao, Q., Kabutey, F.T., Wei, L., Dionysiou, D.D., 2019. Electrochemical activation of persulfate on BDD and DSA anodes: Electrolyte influence, kinetics and mechanisms in the degradation of bisphenol A. J. Hazard. Mater. 121789. https://doi.org/10.1016/j.jhazmat.2019.121789

Dionisio, Dawany, Motheo, A.J., Saez, C., Canizares, P., Rodrigo, M.A., 2019. Competitive anodic oxidation of methyl paraben and propylene glycol: Keys to understand the process. ChemElectroChem 6, 771-778. https://doi.org/10.1002/celc.201801332

Dionisio, D., Motheo, A.J., Sáez, C., Rodrigo, M.A., 2019. Effect of the electrolyte on the electrolysis and photoelectrolysis of synthetic methyl paraben polluted wastewater. Sep. Purif. Technol. 208, 201-207. https://doi.org/10.1016/j.seppur.2018.03.009 
Dionisio, D., Santos, L.H.E., Rodrigo, M.A., Motheo, A.J., 2020. Electro-oxidation of methyl paraben on $\mathrm{DSA}^{\circledR}-\mathrm{Cl}_{2}$ : UV irradiation, mechanistic aspects and energy consumption. Electrochim. Acta 338, 135901. https://doi.org/10.1016/j.electacta.2020.135901

Doroshenko, I., Pogorelov, V., Sablinskas, V., 2013. Infrared absorption spectra of monohydric alcohols. Dataset Pap. Chem. 2013, 329406. https://doi.org/10.7167/2013/329406

Farzinnejad, N., Beigi, A.A.M., Fotouhi, L., Torkestani, K., Ghadirian, H.A., 2005. Electrochemical behavior of some triazine derivatives at glassy carbon electrode in nonaqueous media. J. Electroanal. Chem. 580, 245-254. https://doi.org/10.1016/j.jelechem.2005.03.032

Fornazari, A.L.T., Malpass, G.R.P., Miwa, D.W., Motheo, A.J., 2012. Application of electrochemical degradation of wastewater composed of mixtures of phenol-formaldehyde. Water. Air. Soil Poll. 223, 4895-4904. https://doi.org/10.1007/s11270-012-1245-y

Frontistis, Z., Antonopoulou, M., Venieri, D., Dailianis, S., Konstantinou, I., Mantzavinos, D., 2017. Solar photocatalytic decomposition of ethyl paraben in zinc oxide suspensions. Catal. Today 280, 139-148. https://doi.org/10.1016/j.cattod.2016.06.008

García-Espinoza, J.D., Nacheva, P.M., 2019. Degradation of pharmaceutical compounds in water by oxygenated electrochemical oxidation: Parametric optimization, kinetic studies and toxicity assessment. Sci. Total Environ. 691, 417-429. https://doi.org/10.1016/j.scitotenv.2019.07.118

Garcia-Segura, S., Ocon, J.D., Chong, M.N., 2018. Electrochemical oxidation remediation of real wastewater effluents - A review. Process Saf. Environ. 113, 48-67. https://doi.org/10.1016/j.psep.2017.09.014

Gomes, F.E.R., de Souza, N.E., Galinaro, C.A., Arriveti, L.O.R., de Assis, J.B., Tremiliosi-Filho, G., 2016. Electrochemical degradation of butyl paraben on platinum and glassy carbon 
$\begin{array}{lllll}\text { electrodes. } & \text { J. } & \text { Electroanal. } & \text { Chem. }\end{array}$ https://doi.org/10.1016/j.jelechem.2016.03.016

Gomes, L., Miwa, D.W., Malpass, G.R.P., Motheo, A.J., 2011. Electrochemical degradation of the dye reactive orange 16 using electrochemical flow-cell. J. Brazil. Chem. Soc. 22, 1299-1306. https://doi.org/10.1590/S0103-50532011000700015

Hussain, S., Steter, J.R., Gul, S., Motheo, A.J., 2017. Photo-assisted electrochemical degradation of sulfamethoxazole using a $\mathrm{Ti} / \mathrm{Ru}_{0.3} \mathrm{Ti}_{0.7} \mathrm{O}_{2}$ anode: Mechanistic and kinetic features of the process. J. Environ. Manage. 201, 153-162. https://doi.org/10.1016/j.jenvman.2017.06.043

Inprakhon, P., Wongthongdee, N., Amornsakchai, T., Pongtharankul, T., Sunintaboon, P., Wiemann, L.O., Durand, A., Sieber, V., 2017. Lipase-catalyzed synthesis of sucrose monoester: Increased productivity by combining enzyme pretreatment and non-aqueous biphasic medium. J. Biotechnol. 259, 182-190. https://doi.org/10.1016/j.jbiotec.2017.07.021

Malpass, G.R.P., Miwa, D.W., Machado, S.A.S., Motheo, A.J., 2008. Decolourisation of real textile waste using electrochemical techniques: Effect of electrode composition. J. Hazard. Mater. 156, 170-177. https://doi.org/10.1016/j.jhazmat.2007.12.017

Malpass, G.R.P., Miwa, D.W., Mortari, D.A., Machado, S.A.S., Motheo, A.J., 2007. Decolorisation of real textile waste using electrochemical techniques: Effect of the chloride concentration. Water Res. 41, 2969-2977. https://doi.org/10.1016/j.watres.2007.02.054

Malpass, G.R.P., Miwa, D.W., Santos, R.L., Vieira, E.M., Motheo, A.J., 2012. Unexpected toxicity decrease during photoelectrochemical degradation of atrazine with $\mathrm{NaCl}$. Environ. Chem. Lett. 10, 177-182. https://doi.org/10.1007/s10311-011-0340-4

Malpass, G.R.P., Motheo, A.J., 2001. Galvanostatic oxidation of formaldehyde-methanol solutions on $\mathrm{Ti} / \mathrm{Ru}_{0.3} \mathrm{Ti}_{0.7} \mathrm{O}_{2}$ electrodes using a filter-press cell. J. Appl. Electrochem. 31, 1351-1357. https://doi.org/10.1023/A:1013814831777 
Marselli, B., Garcia-Gomez, J., Michaud, P.-A., Rodrigo, M.A., Comninellis, C., 2003. Electrogeneration of hydroxyl radicals on boron-doped diamond electrodes. J. Electrochem. Soc. 150, D79. https://doi.org/10.1149/1.1553790

Martínez-Huitle, C.A., Rodrigo, M.A., Sirés, I., Scialdone, O., 2015. Single and coupled electrochemical processes and reactors for the abatement of organic water pollutants: a $\begin{array}{lllll}\text { critical } & \text { review. } & \text { Chem. }\end{array}$ https://doi.org/10.1021/acs.chemrev.5b00361

Muñoz-Morales, M., Sáez, C., Cañizares, P., Rodrigo, M.A., 2020. Improvement of electrochemical oxidation efficiency through combination with adsorption processes. J. Environ. Manage. 262. https://doi.org/10.1016/j.jenvman.2020.110364

Muñoz-Morales, M., Sáez, C., Cañizares, P., Rodrigo, M.A., 2019a. Enhanced electrolytic treatment for the removal of clopyralid and lindane. Chemosphere 234, 132-138. https://doi.org/10.1016/j.chemosphere.2019.06.059

Muñoz-Morales, M., Sáez, C., Cañizares, P., Rodrigo, M.A., 2019b. A new electrochemicallybased process for the removal of perchloroethylene from gaseous effluents. Chem. Eng. J. 361, 609-614. https://doi.org/10.1016/j.cej.2018.12.119

Muñoz, M., Llanos, J., Raschitor, A., Cañizares, P., Rodrigo, M.A., 2017. Electrocoagulation as the key for an efficient concentration and removal of oxyfluorfen from liquid wastes. Ind. Eng. Chem. Res. 56, 3091-3097. https://doi.org/10.1021/acs.iecr.7b00347

Ota, K.I., Nakagawa, Y., Takahashi, M., 1984. Reaction products of anodic oxidation of methanol in sulfuric acid solution. J. Electroanal. Chem. 179, 179-186. https://doi.org/10.1016/S00220728(84)80286-7

Parra, K.N., Gul, S., Aquino, J.M., Miwa, D.W., Motheo, A.J., 2016. Electrochemical degradation of tetracycline in artificial urine medium. J. Solid State Electr. 20, 1001-1009. 
https://doi.org/10.1007/s10008-015-2833-8

Pelskov, Y. V., Sakharova, A.Y., Krotova, M.D., Bouilov, L.L., Spitsyn, B. V., 1987. Photoelectrochemical properties of semiconductor diamond. J. Electroanal. Chem. 228, 1927. https://doi.org/10.1016/0022-0728(87)80093-1

Petrović, M., Gonzalez, S., Barceló, D., 2003. Analysis and removal of emerging contaminants in wastewater and drinking water. TrAC - Trend. Anal. Chem. 22, 685-696. https://doi.org/10.1016/S0165-9936(03)01105-1

Rajkumar, D., Kim, J.G., 2006. Oxidation of various reactive dyes with in situ electro-generated active chlorine for textile dyeing industry wastewater treatment. J. Hazard. Mater. 136, 203212. https://doi.org/10.1016/j.jhazmat.2005.11.096

Raschitor, A., Llanos, J., Cañizares, P., Rodrigo, M.A., 2017. Novel integrated electrodialysis/electro-oxidation process for the efficient degradation of 2,4dichlorophenoxyacetic acid. $\quad$ Chemosphere $\quad 182,85-89$. https://doi.org/10.1016/j.chemosphere.2017.04.153

Sánchez-Carretero, A., Sáez, C., Cañizares, P., Rodrigo, M.A., 2011. Electrochemical production of perchlorates using conductive diamond electrolyses. Chem. Eng. J. 166, 710-714. https://doi.org/10.1016/j.cej.2010.11.037

Santos, G.O.S., Eguiluz, K.I.B., Salazar-Banda, G.R., Saez, C., Rodrigo, M.A., 2020a. Photoelectrolysis of clopyralid wastes with a novel laser-prepared $\mathrm{MMO}-\mathrm{RuO}_{2} \mathrm{TiO}_{2}$ anode. Chemosphere 244. https://doi.org/10.1016/j.chemosphere.2019.125455

Santos, G.O.S., Eguiluz, K.I.B., Salazar-Banda, G.R., Sáez, C., Rodrigo, M.A., 2020 b. Understanding the electrolytic generation of sulfate and chlorine oxidative species with different boron-doped diamond anodes. J. Electroanal. Chem. 857, 113756. https://doi.org/10.1016/j.jelechem.2019.113756 
Santos, G.O.S., Gonzaga, I.M.D., Eguiluz, K.I.B., Salazar-Banda, G.R., Saez, C., Rodrigo, M.A., 2020c. Improving biodegradability of clopyralid wastes by photoelectrolysis: The role of the anode material. J. Electroanal. Chem. 864. https://doi.org/10.1016/j.jelechem.2020.114084

Santos, J.P.T. da S., Tonholo, J., de Andrade, A.R., Del Colle, V., Zanta, C.L. de P. e. S., 2020. The electro-oxidation of tetracycline hydrochloride in commercial $\mathrm{DSA}^{\circledR}$ modified by electrodeposited platinum. Environ. Sci. Pollut. R. https://doi.org/10.1007/s11356-02009919-2

Santos, T.É.S., Silva, R.S., Carlesi Jara, C., Eguiluz, K.I.B., Salazar-Banda, G.R., 2014. The influence of the synthesis method of $\mathrm{Ti} / \mathrm{RuO}_{2}$ electrodes on their stability and catalytic activity for electrochemical oxidation of the pesticide carbaryl. Mater. Chem. Phys. 148, 3947. https://doi.org/10.1016/j.matchemphys.2014.07.007

Santos, T.É.S., Silva, R.S., Eguiluz, K.I.B., Salazar-Banda, G.R., 2015. Development of $\mathrm{Ti} /\left(\mathrm{RuO}_{2}\right)_{0.8}\left(\mathrm{MO}_{2}\right)_{0.2}(\mathrm{M}=\mathrm{Ce}, \mathrm{Sn}$ or Ir) anodes for atrazine electro-oxidation. Influence of the synthesis method. Mater. Lett. 146, 4-8. https://doi.org/10.1016/j.matlet.2015.01.145

Saravanan, K., Selvamani, V., Kulangiappar, K., Velayutham, D., Suryanarayanan, V., 2013. Regioselective anodic $\alpha$-methoxylation of 2-oxazolidinone on boron doped diamond in acidic methanol medium. Electrochem. commun. 31-33. https://doi.org/10.1016/j.elecom.2012.12.002

Sirés, I., Brillas, E., Oturan, M.A., Rodrigo, M.A., Panizza, M., 2014. Electrochemical advanced oxidation processes: Today and tomorrow. A review. Environ. Sci. Pollut. R. 21, 8336-8367. https://doi.org/10.1007/s11356-014-2783-1

Souza, F.L., Aquino, J.M., Irikura, K., Miwa, D.W., Rodrigo, M.A., Motheo, A.J., $2014 a$. Electrochemical degradation of the dimethyl phthalate ester on a fluoride-doped Ti/ $\beta-\mathrm{PbO}_{2}$ anode. Chemosphere 109, 187-194. https://doi.org/10.1016/j.chemosphere.2014.02.018 
Souza, F.L., Aquino, J.M., Miwa, D.W., Rodrigo, M.A., Motheo, A.J., 2014b. Photo-assisted electrochemical degradation of the dimethyl phthalate ester on DSA ${ }^{\circledR}$ electrode. J. Environ. Chem. Eng. 2, 811-818. https://doi.org/10.1016/j.jece.2014.02.003

Souza, F.L., Saéz, C., Lanza, M.R.V., Cañizares, P., Rodrigo, M.A., 2016. The effect of the $\mathrm{sp}^{3} / \mathrm{sp}^{2}$ carbon ratio on the electrochemical oxidation of 2,4-D with p-Si BDD anodes. Electrochim. Acta 187, 119-124. https://doi.org/10.1016/j.electacta.2015.11.031

Steter, J.R., Brillas, E., Sires, I., 2018. Solar photoelectro-Fenton treatment of a mixture of parabens spiked into secondary treated wastewater effluent at low input current. Appl. Catal. B-Environ. 224, 410-418. https://doi.org/10.1016/j.apcatb.2017.10.060

Suresh, S., Reddy, I.A.K., Venkatathri, N., 2018. Synthesis of SAPO-16 molecular sieve in nonaqueous medium by microwave method using Hexamethyleneimine as a template. Micropor. Mesopor. Mat. 263, 275-281. https://doi.org/10.1016/j.micromeso.2017.12.008

Tomcsányi, L., De Battisti, A., Hirschberg, G., Varga, K., Liszi, J., 1999. The study of the electrooxidation of chloride at $\mathrm{RuO}_{2} / \mathrm{TiO}_{2}$ electrode using $\mathrm{CV}$ and radiotracer techniques and evaluating by electrochemical kinetic simulation methods. Electrochim. Acta 44, 2463-2472. https://doi.org/10.1016/S0013-4686(98)00381-8

Vedenyapina, M.D., Eremicheva, Y.N., Pavlov, V.A., Vedenyapin, A.A., 2008. Electrochemical degradation of tetracycline. Russ. J. Appl. Chem+ 81, 800-802. https://doi.org/10.1134/S1070427208050145

Wain, A.J., Drouin, L., Compton, R.G., 2006. Voltammetric reduction of perinaphthenone in aqueous and non-aqueous media: An electrochemical ESR investigation. J. Electroanal. Chem. 589, 128-138. https://doi.org/10.1016/j.jelechem.2006.01.025

Zhu, L., Shen, D., Luo, K.H., 2020. A critical review on VOCs adsorption by different porous materials: Species, mechanisms and modification methods. J. Hazard. Mater. 122102. 
https://doi.org/10.1016/j.jhazmat.2020.122102

[1] G. Foti, D. Gandini, C. Comninellis, A. Perret, W. Haenni, Oxidation of organics by intermediates of water discharge on $\mathrm{IrO} 2$ and synthetic diamond anodes, Electrochemical and Solid State Letters, 2 (1999) 228-230.

[2] P. Canizares, C. Saez, J. Lobato, R. Paz, M.A. Rodrigo, Effect of the operating conditions on the oxidation mechanisms in conductive-diamond electrolyses, Journal of the Electrochemical Society, 154 (2007) E37-E44.

[3] P. Canizares, F. Martinez, M. Diaz, J. Garcia-Gomez, M. Rodrigo, C. Comninellis, M. Doyle, J. Winnick, Electrochemical oxidation of aqueous phenol wastes using active and non-active electrodes, Energy and Electrochemical Processes For a Cleaner Environment, Proceedings2001, pp. 59-71.

[4] M.A. Rodrigo, P.A. Michaud, I. Duo, M. Panizza, G. Cerisola, C. Comninellis, Oxidation of 4-chlorophenol at boron-doped diamond electrode for wastewater treatment, Journal of the Electrochemical Society, 148 (2001) D60-D64. 